\title{
Surrogacy in India: from taboo to common practice
}

Annadurai Kalaivani ${ }^{1}$, Mani Geetha ${ }^{1}$, Danasekaran Raja ${ }^{1}$, Jegadeesh Ramasamy ${ }^{2}$

1 Assistant Professors, Department of Community Medicine, Shri Sathya Sai Medical College \& Research Institute, Kancheepuram district, Tamil Nadu

2 Professor, Department of Community Medicine, Shri Sathya Sai Medical College \& Research Institute, Kancheepuram district, Tamil Nadu

Surrogacy is a form of assisted reproduction, whereby a woman agrees to become pregnant for giving birth to a child for others to raise. Two types of surrogacy are practiced: traditional surrogacy and gestational surrogacy. She may be the child's genetic mother (traditional surrogacy) or she may be implanted with an unrelated embryo (gestational surrogacy). Depending on the financial rewards received, it may be commercial or altruistic [1].

Previously, adoption was the only option for those couples with nil chance of bearing a child but the introduction of modern Assisted Reproductive Techniques (ART), has become a blessing for them. Medical procedures like artificial insemination of sperm or transferring fertilized egg has been used in surrogate mother to help those childless couples. Currently, surrogacy is illegal in many countries; in some other countries, it is legal, yet a costly procedure. In India, since 2002, commercial surrogacy has been legalized. In 2005, Indian Council of Medical Research has formulated National Guidelines for Accreditation, Supervision and Regulation of ART Clinics [2].

Realizing the growing demand of surrogacy, Indian government has initiated ART legislation in 2008, drafted in 2010 and finally framed the ART (Regulation) Bill, in 2013, that is yet to be passed in the parliament. This bill proposes restriction of surrogacy to Indian married infertile couples which includes non-resident Indians, persons of Indian origin, overseas citizens of India and foreigners married to Indian citizens. Further it proposes debarring of single person from availing surrogacy services. Currently all Indians, foreign couples and single person can avail the service [3].

Private sector which is currently the sole provider of surrogacy services is given full freedom to expand ART clinics for the dual promotion of medical tourism and surrogacy. India, now a favorite destination of surrogacy because of cost effectiveness and legal reasons, awaits the decision of the parliament on ART Bill. 
With over 3,000 fertility clinics that are providing surrogacy services, Indian surrogacy business is worth more than $\$ 400$ million a year [4]. Average cost of surrogacy ranges between $\$ 10,000$ and $\$$ 30,000 which includes cost of in vitro fertilization, surrogate's fee, insurance coverage, antenatal care, delivery cost, fee for lawyer and doctors. Through a legal contract, surrogate mothers get a monthly salary of equivalent of about $\$ 50$ (3,000 Indian Rupee; 1 Indian Rupee $=0.016591 \$$ ) with a final payment of about $\$ 3,300-6,600$ (200,000 to 400,000 Indian Rupee) after the child birth and the payment increases if it is a multiple pregnancy [5].

With rising infertility rates, growing trend of same sex couples and famous celebrities opting for children from surrogate mothers, surrogacy is no longer considered as a taboo. Previously, it was equated with prostitution, but factors like poverty, illiteracy, unemployment, need of money for children education, medical treatment for family members and need for owning a house are influencing Indian females to rent their wombs for surrogacy leaving behind the traditional values. It's been over 20 years since India's first surrogate child birth, the attitude on surrogacy has changed over the years which has been evident from 40,000 to 45,000 children born through surrogacy in the entire country [5].

With transnational surrogacy constitutes quite a proportion of Indian surrogacy market, the future of Indian surrogacy depends on the decision of parliament on ART Bill, 2013. But there is an urgent need for regulation and monitoring of Indian surrogacy industry to prevent over exploitation of poor Indian women. Surrogacy, even though a controversial issue, is a blessing for both childless couples and the poor surrogate mothers, if utilized in a right manner.

\section{Reference}

1. Nigam A, Ahmed A. Surrogacy: An Indian Perspective. Tropical clinics of Obstetrics and Gynecology 2013; 1 :e2

2. Government of India. ICMR. National guidelines for the accreditation supervision and regulation of ART clinics in India. New Delhi. 2005. Available at http://www.icmr.nic.in/art/art_clinics.htm

3. Malhotra A. Ending discrimination in surrogacy laws. The Hindu, May 3rd 2014

4. United Nations Population Fund. Sama - Resource Group for Women and Health. Birthing A Market-A Study on Commercial Surrogacy. New Delhi, 2012. Available at http://www.samawomenshealth.org/downloads/Birthing\%20A\%20Market.pdf

5. Centre for Social Research (CSR). Surrogate Motherhood - Ethical or Commercial. Available at http://www.womenleadership.in/Csr/SurrogacyReport.pdf 